\title{
Effective Management for the Sustainable Development of Sanatorium-Resort Complexes in the Crimean Republic
}

Igor Nikolaevich Dyshlovoi ${ }^{1}$

\author{
Vladimir Andreevich Lukianenko²
}

\section{Olga Victorovna Prokhorova ${ }^{3}$}

\section{Elena Yurievna Tugolukova ${ }^{4}$}

\begin{abstract}
1V.I. Vernadsky Crimean Federal University, Simferopol, Russian Federation 2V.I. Vernadsky Crimean Federal University, Simferopol, Russian Federation ${ }^{3}$ V.I. Vernadsky Crimean Federal University, Simferopol, Russian Federation ${ }^{4}$ V.I. Vernadsky Crimean Federal University, Simferopol, Russian Federation
\end{abstract}

\section{Doi:10.5901/mjss.2015.v6n4s4p424}

\section{Abstract}

The article covers the problems of regional development and of enhancing the efficiency of Spa-resort complexes with medical facilities, hereinafter referred to as a sanatorium-resort complex (SRC), in the Crimean Republic. The formation of SRC enterprise management is connected with developed hierarchical management structures. The article shows that involving unutilized resources demands a synthesis of goals, within the hierarchy, and corresponding criteria and data. An integral estimation helps to simplify problems and is convenient for a decision-maker (DM). Enterprise ranking and clustering may be accomplished on the basis of these data sets. A minimal tool set, providing a management mechanism is based on the dominant component analysis and on the function of competitive resemblance. Labour intensity of large-scale experiments leads to the necessity of creating an intellectual informational support system for decision-making in SRC management.

Keywords: recreation and sanatorium-resort complex, effective management.

\section{Introduction}

In view of recent changes, the Crimean Republic needs to develop new and more effective approaches to management and to identify the state socio-economic policy, including the development of regional recreational and SR complex management mechanisms for economical and organizational advantage. A policy, which is task-oriented and systematic to control the environmental conditions and regulate the activity of SRCs, is necessary. To that end, it is important to use the huge potential of the Crimean Republic (CR) efficiently.

A primary strategic aim for Crimean Republic development is the formation of an international tourist center. To achieve this it is necessary to reorganize infrastructure, to create a model for year-round sustainability as well as modern and competitive accommodation based off the modernization and reconstruction of currently existing means and facilities currently under republican ownership. First of all, it is essential to ensure that there is a year-round functioning sanatorium-resort sector.

State-private partnerships will allow for mutually profitable state-business interaction to work out a solution to the problem, which the sector is facing. There are also plans to switch to a cluster approach for sanatorium-resort and tourist center economic development in Crimea from 2015 (Dyshlovoi, 2015).

With the aim of organizing the effective management of state-owned sanatorium-resort organizations, the Council of ministers of the Crimean Republic passed a decree on May 14, $2014 \mathrm{Nr}$ 383-r "On coordination of the sanatoriumresort organizations, located in the Crimean republic, during the transitional period". It stated that the Ministry for resorts and tourism in the Crimean Republic will coordinate the work of listed organizations within the territory of the Crimean Republic concerning the questions of resorts and tourism and provide the effective functioning of sanatorium-resort organizations.

The problem of building effective mechanisms for sanatorium-resort complex (SRC) management development in the Crimean Republic remains unsolved and requires further research. 
The quality of management decision-making depends on the recreational development level and SRC organization management mechanisms at all levels of hierarchy. A well-timed supply of management processes with necessary and verified information, which characterizes the processes of serving the customer flow and SRC organizational activity, is essential. Special tools, based on the tasks of analysis, modeling and forecasting of socio-economical processes of SRCs, were developed in order to solve the problem of informational support.

\section{Research Methods}

Research methodology is defined by the specificity of recreational and sanatorium-resort complex management mechanisms and their effectiveness. Sustainable development methods provide social, economical and ecological factors, which are used in management processes modelling (Luk'yanenko, 2013). The Multi-level and multi-criteria character of SRC activity appraisal defined the choice of hierarchical net structures and multi-criteria optimization of such networks with the conditions of limited resources and preferences in the managerial decision-making of DMs. The large spatial dimension of statistical and other data forms and their uncertainty requires additional methods for dimension diminishing and defining main factors and indexes. Convenience, with regard to DM presentation of the data on diagnostics, monitoring and forecasting, predetermined the choice in favor of dominant component analysis for decisionmaking tasks and effectiveness appraisal (Dyshlovoi, 2010; Kozlova and Ivanova, 2012; Kozlova, M.G. and Luk'yanenko, 2013). The listed approaches are developed and applied to both recreational and SRC tasks.

\section{Results}

\subsection{Development and management process modeling}

There is a necessity in research, aimed at the creation of informational systems, to react quickly and adapt to changes which emerge in the economical environment. Such systems are a must to provide the necessary functioning of already existing approaches and models.

Regional SRC process modeling, by means of using unutilized resources, greatly requires specific aims, goals and achievable results. At the level of each target unit, it is important to define criteria in the correct manner, so that the data obtained will help in the appraisal process for SRC activity and management mechanisms (Dyshlovoi, 2015; Luk'yanenko, 2013).

One of the aims of the project is solving the problems of development process modeling and regional SRC management by involving unutilized resources and effective mechanisms.

The problems connected with SCR enterprise management demands a systematic approach (Moiseev, 1981).

It is quite difficult to define objectives, and hierarchy composition along with the very definition of "objective" at the highest level of hierarchy. Therefore it is necessary define the very criteria of objective achievement appraisal as well as the system of differing limitations, requirements, indicators and integral criterion. To define realistic aims for the SRC is fairly impossible. The objectives of SCR enterprise active development may be viewed as goals and programs for effective regional development (project complexes), providing the state a socio-economical effect. The following problem exists when combining the structural and functional aspects of goal achievement, in forming the system of decisionmaking, concerning the implementation of development programs projects. The functionality of SCRs depends on the way they are being managed with each individual enterprise having its own aims and interests. To manage it effectively, formulation of low-level aims (at the individual enterprise level) is not enough. Confidence in the possibility of SCR aim achievement is necessary, which means that high-level requirements will be fulfilled at the lower level. This therefore becomes a necessity in the economical mechanism of organization, which works according to the principles of hierarchical management with feedback, and also through use of a relevant toolkit.

The developed practice of various hierarchical structures (radial, diamond) is used on three levels: 1) state level; 2) regional level (sector, SRC); 3) enterprise level (SRC enterprises and connections between them).

Recreational and SRC enterprises have quite complicated relations (often characterized by conflicts) with other enterprises of SRC, cluster and of destination and hierarchical organization structures. Branch hierarchy is of a distributional character, i.e. an enterprise belongs to the territory of both the city and region, and therefore is an element of regional infrastructure; is a part of the regional management hierarchical system.

As a rule, objects from an inferior level cannot have managerial influence upon a higher level. State management hierarchy is represented by a complex of diamond structures with branch and regional management implemented within the structure. Management organization according to branch and regional principle cannot contradict each other and 
must resist self-organizing processes.

The rational distribution of management provides the work effectiveness of all SRC enterprises. Collective decision-making may provide an effective compromise, e.g., The Pareto principle of effective decisions (Nogin, 2002). However, it is known that Pareto compromises are non-stable in many cases. Germeyer type systems are the most suitable for this sphere (Moiseev, 1981). It is necessary, for this type of system, that each and every enterprise compromises on some of its interests in order to achieve mutual objectives. According to N.N. Moiseev (Moiseev, 1981), the simplest variant of the management model is represented by N SRC enterprises with performance functions $f_{i}\left(x_{i}\right)$, $i=1,2, \mathrm{~K}, N$, where the resource $x_{i}$ is at $i$ enterprise's disposal. The mutual aim is described by the performance function $F\left(y_{1}, y_{2}, \mathrm{~K}, y_{N}\right)$. Its value depends on the activity of all the enterprises and on the resource $y_{i}$, which is provided by $i$ enterprise for the achievement of the mutual objective. As a result, we have a multi-criteria vector hierarchical optimization formula:

$$
F\left(y_{1}, \mathrm{~K}, y_{N}\right) \rightarrow \max , f_{i}\left(x_{i}\right) \rightarrow \max , x_{i}+y_{i}=a_{i}, i=1,2, \mathrm{~K}, N
$$

Where $a_{i}$ - represents an aggregate resource, which is at $i$ enterprise's disposal.

Germeyer-Vatel's theorem is valid for such types of systems. Assume $f_{i} F$ - are the monotonically increasing functions. Then there are stable solutions, at least one of which is effective.

Based on this result, the situation algorithm lends itself to grading all enterprises.

$$
\lambda_{1} f_{1}\left(a_{1}\right) \geq \lambda_{2} f_{2}\left(a_{2}\right) \geq \mathrm{K} \geq \lambda_{N} f_{N}\left(a_{N}\right)
$$

In which case there is such $p \leq N$, that for every $i \geq p, y_{i}=0$, i.e. enterprises which have small $\lambda_{i} f_{i}\left(x_{i}\right)$, may spend all their resources on the achievement of their internal objectives. This means that a group of enterprises does not take part in combined events (distribute the remaining resources ${ }^{y_{i}}$, which are defined by the system of equation $\left.\lambda_{i} f_{i}\left(y_{i}\right)=F\left(y_{1}, \mathrm{~K}, y_{p}, 0 \mathrm{~K} 0\right), i=1, \mathrm{~K}, p\right)$.

Theoretical results of this type are also of practical use. Grading (rating) enterprises and their clustering also helps to separate those having low service technology or units that have low interest in regards to achieving mutual SRC aims ( $\lambda_{i}$ is low). Such information is a result of economical and organizational mechanism functioning. Information flow, ascending according to hierarchy level, conclusion analysis and formation as well as the descending flow of rating, comparative, analytical and other types of information necessary for all enterprises are both of equal importance.

It is possible to come to the conclusion that the choice of SRC objectives must be defined by a regional strategic center of coordination, as well as analyze, conform and check the completeness and validity of all hierarchical objectives. Self-regulating SRC organization together with partial state partnership may be favorable here.

\subsection{Hierarchical system of integral indicators}

The following SRC decision-making support and management mechanism modeling is connected with the construction of the corresponding analysis, synthesis and forecasting systems based on the hierarchical structures (Saati, 1993). These structures are inherent to SRC management and naturally reflect innovative SRC enterprise clustering processes (Kozlova, Luk'yanenko and Ivanova, 2013), and to those that are connected with them.

Management mechanism support tools use the initial statistical data from enterprise and branch activity, scientific assessment and knowledge, forecasting and case data. Initial data on the enterprises forms the lower hierarchical level. They are quantitative and qualitative, of different dimension and certainty. Comparative analysis demands their normalization, which depends on the choice of specific valuation. As a rule there is an annual value (or for varying time periods), its lower valuation limits; threshold limit value; lower norm; high norm; high valuation limit; high valuation limit indicator; ideal value in relation to the criterion set; comparative valuation, etc. Further to this is information about the growth or decline indicator for a certain period; belonging to a certain diapason; about the necessity of finding the significance of the indicator (factor). Processing of this type of information requires the creation of a subsystem, which can monitor the current dynamics of SRC activity (data standardization, formation of the integral appraisal of changes, regularities analysis and detection of any changes).

To set the parameters of hierarchical structures we need to separate cases and employ instructional information. Analysis of the received integral indicators is accompanied by the extraction of knowledge, necessary for managerial decision-making and is carried out along With strategic analysis, forecasting, foreseeing and planning in conformity with 
the developed and proved hierarchy objectives (Kozlova, Luk'yanenko and Ivanova, 2012).

It is important for a DM to operate with a small number of integral indicators. As shown earlier, good decisionmaking leads to the necessity of solving multi-criteria tasks, which are, as a rule, of a distributional nature with a resources limit (Moiseev, 1981; Nogin, 2002).

SRC enterprise and management mechanisms working efficiency may be appraised according to the integral indicators, formed on the basis of a small number of initial indicators. However, due to drawbacks in the existing system of data gathering (statistical data) it is necessary to involve proxy indicators and also indicators, received by analogy, as a result of forecasting and strategic planning.

For the convenience of a DM, the integral indicators formation system must be simple and must contain some tools, which may be inserted at the level of an enterprise or of an SRC.

Dominant component analysis is a basic tool for multidimensional statistical analysis (Ayvazyan, 1998).

Dominant component analysis helps to distinguish the spatial dimensions of the attribute indicators; separate significant indicators and their contribution to the information (according to dispersion level); to form a block of weakly changing indicators and indexes, corresponding to them, which may react to eventful and negative changes to enterprise activity and to external conditions; integral indicator convolution according to levels and units allows a DM to operate with a minimal number of integral indicators (indexes); schedules of these indicators reflect high quality processes; lower level indicator forecasting automatically forms a forecasting for the higher level of the hierarchy.

The necessity of a comprehensive appraisal of one or several enterprises of an SRC cluster required involving clustering tools based on a competitive resemblance function. Such a function may allow for the construction of an analogue of life cycle function (identification of which is a difficult task).

Here is a simplified variant of the working algorithm with indicators.

We shall set the primary indicator via:

$a_{i j}^{k}(t), i=1,2, \mathrm{~K}, m, j=1,2, \mathrm{~K}, n_{k}, t=1,2, \mathrm{~K}, T, k=1,2, \mathrm{~K}, K$,

where

$m$ - the number of objects

$n_{k}$ - the number of primary indicators in $k$ sub-group $k=1,2, \mathrm{~K}, K$;

$[1, T]-$ the period, during which primary indicators were measured;

$\sum_{k=1}^{K} n_{k}=n-$

$K$ - number of subgroups of indicators.

Scaling primary indicators is conducted in order to standardize them and to reduce dimensionless numbers. $1 \leq i \leq m$

We find the maximum and minimum value for each $a_{i j}^{k}(t)$ indicator according to the selected SCR enterprise

$$
c_{j}^{k}(t)=\max _{1 \leq i \leq m} a_{i j}^{k}(t), b_{j}^{k}(t)=\min _{1 \leq i \leq m} a_{i j}^{k}(t), j=1,2, \mathrm{~K} n_{k}, k=1,2, \mathrm{~K}, K .
$$

We transform the initial value ${ }^{a_{i j}^{k}(t)}$ into a new $\alpha_{i j}^{k}(t) \in[0,1]$ with the following formulas:

$\alpha_{i j}^{k}(t)=\left(a_{i j}^{k}(t)-b_{j}^{k}(t)\right) /\left(\mathrm{c}_{j}^{k}(\mathrm{t})-b_{j}^{k}(t)\right)-$ for positive indicators

$\alpha_{i j}^{k}(t)=\left(\mathrm{c}_{j}^{k}(t)-a_{i j}^{k}(t)\right) /\left(\mathrm{c}_{j}^{k}(\mathrm{t})-b_{j}^{k}(t)\right)-$ for negative indicators

Values of received transformed indicators belong to the standard interval $(0,1)$ and characterize the proximity of the initial indicators and maximum and minimum values for the selected group of enterprises. This transformation preserves the qualitative behavior of the initial data. Values $\alpha_{i j}^{k}(t)$ are presented in tables for each fixed value $t \in[0, T]$ and $k \in(1, K)$.

The choice of dominant components and indicators, forming integral indicators according to the indicators units, is achieved through the Matlab pack for each table (if the dimensions are low) or for a single enterprise: 


$$
y_{i}=\sum_{j=1}^{n} a_{i j} x_{j}, \quad i=1, \mathrm{~K}, K,
$$

where ${ }^{a_{i j}}{ }^{-}$coefficient, $(p c=P-$ matrix).

Centralized and standardized data $x_{1}, \mathrm{~K}, x_{12}$ is used instead of initial data $X_{1}, \mathrm{~K} X_{12}$ when using the dominant components method. A strong connection is set with the corresponding indicators $x_{i}$ (if all modulus matrix elements are more than 0,6 ) according to the load matrix $A$. Dominant component $y_{i}$ informativeness is defined with the proper values of the dominant components matrix (dispersion part).

Received dominant components are interpreted as integral indicators. To get the next hierarchical level integral indicators to the received dominant components we use the procedure of dominant component pivoting:

$$
I(t)=\sum_{i=1}^{K} \alpha_{i} y_{i}(t),
$$

Where the coefficients ${ }^{a_{i}}$ correspond to the possibility (informativeness) of the component $y_{i}$.

This approach eliminates the subjective nature of coefficients choice.

This procedure was analyzed using different data. We used a set consisting of 31 indicators for the relevant SRC enterprises in Yevpatoria, Saky, Yalta, Alushta (6-8 enterprises from each). 3-5 main components played representative roles. Let us make an example of integral indexes for the "Pobeda" sanatorium in Yevpatoria.

\begin{tabular}{|c|c|c|c|c|c|c|c|}
\hline Indicators (thousands of hryvnia, UAH) & 2008 & 2009 & 2010 & 2011 & 2012 & 2013 & 2014 \\
\hline implementation value (X1) & 7601,7 & 9711,9 & 9310,7 & 15363,9 & 7746,4 & 9206,7 & 13325,3 \\
\hline VAT $(\mathrm{X} 2)$ & 928,1 & 1173,3 & 1322 & 2181,4 & 1018,6 & 1170,6 & 1791,7 \\
\hline Net income $(X 3)$ & 6673,6 & 8538,6 & 7988,7 & 13182,5 & 6727,8 & 8036,1 & 11533,6 \\
\hline Production expenses (X4) & 6416 & 8008,3 & 7576,7 & 11603,1 & 7522 & 8089,7 & 9428,2 \\
\hline Prime cost (X5) & 6416 & 8008,3 & 7576,7 & 11603,1 & 7522 & 8089,7 & 9428,2 \\
\hline Integral indicator $I$ & -1.37 & -0.70 & -0.33 & мар.22 & -1.02 & -0.90 & 01.ноя \\
\hline
\end{tabular}

Table 1. The integral indexes for the "Pobeda" sanatorium in Yevpatoria

An example of integral indicator schedules is represented by the figure 1 and 2.

This type of visualization is demonstrative and convenient for a DM.

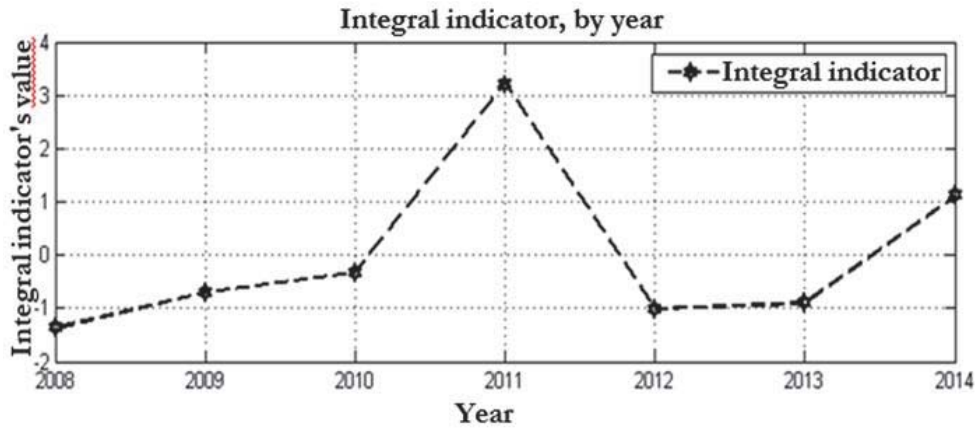

Figure 1. Integral indicator/years, corresponding to Table 1. 




Figure 2. Integral indicator of unit expenses

Here is the algorithm that we used for processing the data scope and characterizing the activity of sanatorium-resorts and recreational complexes in $\mathrm{CR}$ :

1. Gathering statistical, expert and other required data types to form a data scope. Preliminary processing, setting minimal, maximal, target and case values.

2. Data clustering according to the principles of sustainable development (separating social, economical, ecological units and units inferior to them).

3. Reducing the dimensions of attribute space and data clustering based on the dominant components analysis. Separating dominant components which correspond to the sustainable development of units.

4. Separating significant indicators and removing integral indicators and invariable indicators from the calculations.

5. Separating indicators, which may change in the future under internal and external influences (situational influence, changes to flow and number of visitors, resources, etc) from changeable indicators, which have no influence on the values of dominant components. From this base the data scope for indicative indicator calculations is formed.

6. Dominant components are separated for the transformed units, for which total informational constituents will be more than $90 \%$ (parameter may vary).

7. On the basis of received dominant components, integral unit indicators (indexes) are formed, from which we get integral indicators of a higher level of hierarchy with the help of a convolution of primary indicators.

8. Comparative analysis of the received integral indicators of the enterprises or branch in relation to the values (forecasting, of threshold criteria, optimal, ideal) is made.

\subsection{Clustering and grading of enterprises}

The results obtained are needed for use in the system of management at the state enterprise level, to analyze, monitor and forecast sustainable development of sanatorium-resort and recreational complexes.

Note that dominant components are formed according to every block of information and integral indicator. Groups of integral indicators set a multi-criteria profile for the activity of an object under research. Proxy indicators and indexes may be added. The choice of model indicators, characterizing clusters of enterprises, is important, but is only possible after the installation of a system of data processing, working out case and forecasting values and expert appraisals. The level of effective management corresponds to the system of aims for sustainable and balanced development. Effectiveness level appraisal is defined as the appraisal of the aim achievement, which is brought up to a state of a qualitative appraisal of indicators, specifying the aims. Setting milestones is a complex independent task requiring further examination.

The clustering of enterprises within a specific territory and their grading may also be carried out on the basis of integral indicators, received by using dominant components analysis.

Clustering processes are objective and natural. The identification of promising clusters from the perspective of sustainable development is an urgent task, which requires a more detailed formation of unit purposes and hierarchical structure indicators, which should include integral indicators of attractiveness, competitiveness, accessibility, etc. 
Enterprise and cluster level should be provided with information, tools, and management technology, reflecting their activities. Considering the following problems: seasonality; the uneven flow of tourists; modernization; infrastructure changes; cost minimization and profit maximization (not at the expense of social component) is an important task.

The abundance of data necessary to take a reasonable account of the comparative analysis data requires an adequate solution. If there is the possibility to choose the worst and the best objects from the entire set of data, it is possible to implement clustering (ranking) for the rest of the enterprises on the basis of competitive similarity function. The worst and best enterprises may be virtual and represented by experts to achieve the desired result.

If we take a moment to consider the simplest version, using the competitive similarities function. Then in relation to the objective of the work on control mechanism effectiveness assessment, we will be comparing companies on management effectiveness. Let the enterprise activity be characterized by known indicators in relation to managerial influences (e.g., worst now or in a given period). Now we can compare it with other companies and the selected competitive one, using the competition similarities function:

$$
F(z, x \mid y)=\frac{r(z, y)-r(z, x)}{r(z, y)+r(z, x)}
$$

Where $r(z, x), r(z, y)$ - the distance from the object (enterprise) $z$ to the object $x$ and to the object $y$ correspondingly. $F$ function changes from -1 (if $z$ is equal to $y$ ) to 1 (if $z$ is equal to $x$ ). $F$ function can be compared with the management efficiency indicator (or rating) by the formula (as a percentage):

$$
I(t)=\frac{1}{2}(1-F) 100 \%
$$

If the enterprise $y$ (competitor) is the best. Or by the formula"

$$
I(t)=\frac{1}{2}(F \quad 1) 100 \%
$$

if the enterprise-competitor "

The distance between the objects (enterprises) can be introduced differently.

A normalized ratio with the number $j$ for the $i$-th enterprise was marked as $\alpha_{i j}(t)$, where $t$ is the chosen period. While for function $F$ we denote indicators, which meet object $x$ through ${ }^{\alpha}(t)$, object $y$ through ${ }^{\alpha_{y j}(t)}$, and object $z$ through ${ }^{\alpha_{z j}(t)}$, then

$$
\begin{aligned}
& r(z, x)(t)=\left(\sum_{j=1}^{n}\left(\alpha_{x j}(t)-\alpha_{z j}(t)\right)^{2}\right)^{1 / 2} \\
& r(z, \mathrm{y})(t)=\left(\sum_{j=1}^{n}\left(\alpha_{y j}(t)-\alpha_{z j}(t)\right)^{2}\right)^{1 / 2}
\end{aligned}
$$

These equations are substituted into the function of competitive similarities. Depending on current statistics of performance indicators, thresholds are defined in an expert manner, for example for $10 \%$, management measures should be applied to improve performance up to $50 \%$. However these values are relative.

For the aforementioned enterprises, a ranking place concerning SCC enterprises from selected cities within a fixed period of time. In the next period, they analyzed changes in the cluster of conditionally best enterprises and the need to adopt management measures by the enterprise or the need for external interference. The small group of indicators showed a quality match with the expected distribution of enterprises.

\section{Discussion and Conclusion}

The reduction in the dimension of the data needed to apply a competitive similarity function is possible when using integral indicators or major components. The development of this direction is associated with intellectualized computer data processing systems. Under such systems, it is possible to carry out model, large-scale practical experiments that take into account the multi-criterion nature of the tasks and the need for forecasting assessments.

It is known that even for simple deterministic systems there is a horizon of forecasting, which can not be overcome using advanced algorithms and computer technologies.

For the effective management of recreation and sport-concert complexes (and other related centers) there is a need to develop tools and technologies to be able to forecast and predict the conducted system quality studied. For many 
complex hierarchical systems, it becomes difficult to use data describing the process background and for configuring parameters (identification) of predictive models. Besides, it is necessary to involve heuristic and non-computer algorithms for the intellectualization of information processing processes in forecasting.

Such algorithms are based on a person's thinking, perception and ability to anticipate. The most appropriate algorithms must operate with multiple parameters from a set of parameters that describe the system. Interestingly the representative parameters of the projection in the subspace of a smaller dimension adequately reflect the processes taking place in the greater space of variables. To some extent, the proposed technology of integral indicators solves this problem. Computer technologies, based on the proposed algorithms, allow you to summarize many indicators characterizing the system into several indicators, used in the mechanisms of making managerial decisions.

Multi-criteria modeling, competitive similarities functions and a set of integral indicators received adequately reflects the changes of activity of SRC enterprises and can serve as a content relevant management support system for analysis, diagnosis, prediction and effective decisions making.

Addressing these challenges requires the establishment of a regional monitoring and forecasting system based on accessible, complete and accurate information. Crimea's limited accessibility (isolation) and resource flow controllability are favorable for the creation of a convenient test site for predictive management strategies.

\section{References}

Ayvazyan, (1998). S.A. Prikladnaya statistika i osnovy ekonometriyi. Moscow.Uchebnik dlya vuzov.. -: UNITY,- 1022p. [in Russian]

Dyshlovoi, I.N. (2015). Sostoyaniye, problem I perspektivy razvitiya sanatorno-kurortnoy I turisticheskoy otrasli respubliki Krym II Sovremennyie problem servisa i turisma. Nauchno-prakticheskiy zhurnal.-, t. 9, №1. - P. 51-59. [in Russian]

Dyshlovoi, I.N. (2010).Sovremennyie organizatsionniye resheniya regional'nogo razvitiya rekreatsiyi I turizma: klasterizatsiya I komplexniye programmy. - Odessa. Monographiya. - 212 p. [in Russian]

Kozlova, M.G., Luk'yanenko, V.A., Ivanova, U.E. (2012). Modelirovaniye prinyatiya sotsial'no-ekonomicheskikh resheniy v uslloviyakh neopredelyonnosti // Kultura narodov Prichernomorya. - P. 228-235. [in Russian]

Kozlova, M.G., Luk'yanenko, V.A., Ivanova, U.E. (2012). Ispol'zovaniye analogii v sinteze modeley prognozirovaniya sotsial'noekonomicheskikh processov /I Sevastopol'Analiz,modelirovaniy, upravleniye, razvitiye ekonomicheskikh system: sbornik nauchnikh trudov VI Mezhdunarodnoy shkoy-simpoziuma AMUR -2012, , 17-23 of September- P. 188-191. [in Russian]

Kozlova, M.G., Luk'yanenko, V.A., Ivanova, U.E. (2013). Klasterizatsiya ob'ektov s ierarkhicheskoy strukturoy /I Finansovyie rynki I investitsionnyiye protsessy: tezisy dokladov mezhdunarodnoy nauchno-praktichesloy konferentsiyi, Partenit, 15-16 of October I pod.red. M. ЮU. Kussogo. - Simpheropol': TNU, 2013. - P. 59-62. [in Russian]

Luk'yanenko V. A. (2013). Matematicheskoye modelirovaniye effektivnosti funktsionirovaniya sotsial'no-ekonomicheskikh system/l Analiz, modelirovaniye, upravleniye, razvitie ekonomicheskikh system: sbornik nauchnykh trudov VII Mezhdunarodnoy shkolysimposiums AMUR-2013, Sevastopol', $12-21$ sentyabrya / Pod.red. dotsenta A. B. Sigala. - Simferopol': TNU im.V. I. Vernandskogo, 2013. - P. 251-255. [in Russian]

Moiseev N.N. (1981). Matematicheskiye zadachi sistembogo analizal N.N.Moiseev / N.N.Moiseev. - M.: Nauka, - 488 p. [in Russian] Nogin V.D. (2002). Prinyatie resheniy v mnogokriterial'noy srede:kolichestvenniy podkhod. -Moscow.: FIZMATLIT,- 176 p. [in Russian]

Saati, T. (1993). Metod analiza ierarkhiy: Prinyatiye resheniy. Metod analiza ierarkhiy: Translated from English by R. Vagnidze. - M.: Radio I svyaz', - 316 p. [in Russian] 